\title{
CRESCIMENTO E PERCENTUAL DE EMERGÊNCIA DE PLÂNTULAS DE CITRUMELEIRO 'SWINGLE' EM FUNČ̃̃O DOS SUBSTRATOS E DAS DOSES DE CORRETIVO À BASE DE LITHOTHAMNIUM, APÓS CEM DIAS DASEMEADURA ${ }^{1}$
}

\author{
Growth and percentage of emergence of citrumeleiro "Swingle" seedlings in relation to \\ substrates and doses of Lithothamnium based correctives, after a hundred days from 'Swingle'
}

\author{
Paulo Octavio de Lima e Costa Araújo², Francisco César Gonçalves³ ${ }^{3}$ José Darlan Ramos ${ }^{4}$, \\ Nilton Nagib Jorge Chalfun ${ }^{4}$, Gabriel José de Carvalho ${ }^{4}$
}

\begin{abstract}
RESUMO
O experimento foi conduzido no telado do pomar da Universidade Federal de Lavras (UFLA), durante o período de novembro de 2003 a fevereiro de 2004. Realizado com o objetivo de avaliar o efeito de seis diferentes substratos (convencional, Plantmax ${ }^{\circledR}$, composto I, composto II, vermiculita e húmus), interagindo com três doses do corretivo à base de Lithothamnium, $0 \%, 5 \%$ e 10\% (v/ v), sobre o crescimento do citrumeleiro 'Swingle', até o momento da repicagem. Foram utilizados tubetes plásticos cônicos com volume de $75 \mathrm{~mL}$, acondicionados em bandejas com capacidade para 198 tubetes. O delineamento experimental utilizado foi blocos casualizados, em esquema fatorial de $6 \times 3$, sendo os fatores compostos pelos seis diferentes substratos e três diferentes doses do corretivo à base de Lithothamnium, compondo assim, dezoito tratamentos com quatro repetições, sendo cada parcela composta por vinte e duas plântulas. Decorridos cem dias após a semeadura, as plântulas foram retiradas dos tubetes, seccionadas na base do coleto,e registrados os comprimentos da parte aérea e da raiz. Em seguida a biomassa seca da raiz e da parte aérea foram avaliadas. Verificou-se que o húmus e o composto I, isoladamente apresentaram os melhores resultados de crescimento. O corretivo à base de Lithothamnium mostrou ser uma alternativa de incremento nutricional para o crescimento de mudas de citrumeleiro 'Swingle', em condições de $\mathrm{pH}$ baixas, e com pouca disponibilidade de $\mathrm{Ca}$ e $\mathrm{Mg}$.
\end{abstract}

Termos para indexação: Muda cítrica, porta-enxerto, alga calcária.

\section{ABSTRACT}

This experiment was established aiming at evaluating the effect of six different substrates (conventional, Plantmax ${ }^{\circledR}$, compost I, compost II, vermiculite, and muck), interacting with three different Lithothamnium doses, $0 \%, 5 \%$ and $10 \%$ (v/v), over the growth of citrumelo "Swingle" plantlets, until the moment of chiming. The experiment was conducted within the orchard of the Federal University of Lavras, in the state of Minas Gerais, Brazil, during the period of November 2003 until February 2004. The experimental design used was random blocks, in a factorial squeme of $6 \times 3$, with the factors constituted by six different substrates and three different Lithothamnium doses, composing thus, eighteen treatments with four repetitions. Each parcel was composed by twenty two plants. One hundred days after the planting, all the plantlets were taken off the plastic tubes, washed under tap water, and were sectioned in the base of the stem. Thus, the data of the length of each of the parts were recorded. Afterwards, the parts of the plantlets, were placed inside paper bags and transferred to forced air drying hoods, at a temperature of $75^{\circ} \mathrm{C}$, during a period of $72 \mathrm{~h}$. The dry weight of the canopy and root system were registered. It was observed that muck and compost I, separately, presented the best results in terms of growth and amount of dry matter. Lithothamnium evidenced as an alternative to increase nutrient availability to the citrumelo growth plantlets, but only when the $\mathrm{pH}$ conditions and the availability of $\mathrm{Ca}$ and $\mathrm{Mg}$ were low.

Index terms: Citric, plantlets, calcified seaweed.

\section{(Recebido em 23 de março de 2005 e aprovado em 9 de maio de 2006)}

\section{INTRODUÇÃO}

Desde a introdução da cultura dos citros no Brasil no século XVI até o final do século XIX, as plantas cítricas foram propagadas por sementes (POMPEU JÚNIOR, 1991). Com o advento da indústria cítrica no início do século passado iniciou-se a utilização de plantas enxertadas em plantios comerciais, utilizando-se como porta-enxerto a laranjeira 'Caipira' (Citrus sinensis (L.) Osbeck) em larga escala. Sua baixa resistência à seca, e a gomose foram determinantes para a sua substituição pela laranjeira "Azeda" (Citrus aurantium L.), cuja utilização foi importante até a década de 40 (POMPEU JÚNIOR, 2001).

A introdução do vírus da tristeza (CTV), em 1937, e sua disseminação rápida, tendo como vetor o pulgão preto

\footnotetext{
${ }^{1}$ Parte da dissertação apresentada à Universidade Federal de Lavras/UFLA, pelo primeiro autor, para obtenção do grau de Mestre em Agronomia na área de Fitotecnia.

Engenheiro Agrônomo, M.Sc., Professor da Escola Agrotécnica Federal de Barbacena - poctavio@ufla.br

${ }^{3}$ Engenheiro Agrônomo, M.Sc., Professor do CEFET de Rio Pomba.

${ }^{4}$ Engenheiro Agrônomo, Dr.‥, Professor do Departamento de Agricultura/DAG da Universidade Federal de Lavras/UFLA - Cx. P. 3037 - 37.200-000 Lavras, MG.
} 
(Toxoptera citricidus Kirk.) que levou à morte as plantas enxertadas em laranjeira 'Azeda', teve grande impacto sobre a citricultura, pois $90 \%$ do plantio comercial eram sobre esta, tornando-se urgente a seleção de porta-enxertos resistentes.

A pesquisa proporcionou a renovação da citricultura brasileira com o porta-enxerto, limoeiro 'Cravo' (Citrus limonia Osbeck cv. Cravo), que a partir dos anos 60 , foi instalada praticamente sobre este único portaenxerto, tolerante ao vírus da 'Tristeza' e à seca (POMPEU JÚNIOR, 1991), mas incorrendo no mesmo erro do passado.

A intolerância do limoeiro 'Cravo' ao declínio pressionou por uma nova busca no sentido de diversificação de porta-enxertos, sendo que tangerineira 'Cleópatra', limoeiro 'Volkameriano' (Citrus volkameriano Tan. e Pasq.), tangerineira 'Sunki' (Citrus sunki Hort.) e citrumeleiro 'Swingle' (Citrus paradisi Mac x Poncirus trifoliata L. Raf.) mostraram-se boas alternativas para a diversificação (POMPEU JÚNIOR, 2001).

Com o aparecimento da doença chamada de morte súbita dos citros (MSC), houve uma necessidade ainda maior de se encontrar porta-enxertos tolerantes a essa doença. O citrumeleiro 'Swingle'tem se mostrado tolerante a esse mal e devido a isto houve grande procura de sementes e mudas de citrumeleiro 'Swingle'a partir do aparecimento do MSC.

O citrumeleiro 'Swingle' é um híbrido obtido na Flórida em 1907 pelo cientista W. T. 'Swingle', que polinizou flores de pomelo 'Duncan' (Citrus paradisi) com flores de 'Trifoliata' (Poncirus trifoliata) (AGROCITROS MUDAS E PRODUTOS AGRÍCOLAS LTDA, 2004). Nos viveiros de citros em São Paulo nos últimos anos o citrumeleiro 'Swingle' e a tangerineira 'Cleópatra', têm ocupado a segunda e terceira posições na utilização, perfazendo pouco mais de $10 \%$ das propagações. Eles têm sido utilizados como sub-enxertos no caso da morte súbita de citros (MSC).

Os substratos para sementeiras de citros podem ser convencionais ou produtos comerciais, compostos de casca de pinus, vermiculita, materiais orgânicos e diversas outras composições podem ser utilizadas desde que sejam leves, porosos com boa drenagem, isentos de patógenos de solo e não sujeitos à fermentação (CARVALHO, 2001).

Cuidados essenciais devem ser tomados na utilização de substratos comerciais em relação à nutrição mineral, pois, os substratos são constituídos de materiais quase inertes (vermiculita e compostos), diferentes do substrato convencional que leva terra, esterco e adubo (MATIELLO et al., 2000).
O corretivo à base de Lithothamnium é simples, natural, derivado de uma alga marinha do gênero Lithothamnium, apresentando a seguinte composição: matérias minerais (950 a $995 \mathrm{~g} \mathrm{~kg}^{-1}$ ): 625 a $750 \mathrm{~g} \mathrm{~kg}^{-1}$ de carbonato de cálcio (250 a 300g de $\mathrm{Ca} \mathrm{kg}^{-1}$ ) e 59,5 a 115,5g $\mathrm{kg}^{-1}$ de carbonato de magnésio (17 a $33 \mathrm{~g} \mathrm{Mg} \mathrm{kg}^{-1}$ ), o restante 265,5 a $129,5 \mathrm{~g} \mathrm{~kg}^{-1}$ é constituído de outros minerais, e 50 a $5 \mathrm{~g} \mathrm{~kg}^{-1}$ de material na fração orgânica (LE BLEU, 1983).

A possibilidade de uso do corretivo à base Lithothamnium para correção de solos ácidos e deficientes em $\mathrm{Ca}$ e $\mathrm{Mg}$ com a finalidade de elevar o $\mathrm{pH}$ do solo, neutralizar os efeitos de elementos tóxicos e fornecer $\mathrm{Ca}$ e Mg como nutrientes, é real. Deve-se considerar, também, que o suprimento de $\mathrm{Ca}$ constitui um dos principais fatores necessários para o adequado estabelecimento das culturas logo após a germinação. O experimento foi realizado com o objetivo de avaliar o efeito de seis diferentes substratos (convencional, Plantmax ${ }^{\circledR}$, composto I, composto II, vermiculita e húmus), interagindo com três doses do corretivo à base de Lithothamnium, $0 \%, 5 \%$ e $10 \%$ (v/v), sobre o crescimento do citrumeleiro 'Swingle', até o momento da repicagem.

\section{MATERIAL E MÉTODOS}

O experimento foi conduzido sob telado de $50 \%$ de luz, no período de novembro de 2003 a fevereiro de 2004, no setor de Fruticultura da Universidade Federal de Lavras, município de Lavras, MG. A cidade está situada a 21 ¹4'06" de latitude sul e $45^{\circ} 00^{\prime} 00^{\prime \prime}$ de longitude oeste, a uma altitude de $918 \mathrm{~m}$.

As plantas utilizadas para avaliação foram obtidas a partir de sementes de citrumeleiro 'Swingle' (Citrus paradisi Mac X Poncirus trifoliata L.Raf.). As sementes foram extraídas de frutos maduros das plantas matrizes de porta-enxerto, pertencentes ao pomar da UFLA (Universidade Federal de Lavras) durante o mês de julho de 2003. Após lavagem e seleção foram acondicionadas em sacos plásticos e colocadas sob refrigeração ficando assim até a semeadura em novembro de 2003.

Seis substratos foram utilizados para a semeadura das sementes e desenvolvimento das mudas: substrato comercial, Plantmax ${ }^{\circledR ;}$ substrato convencional composto de solo, esterco de boi curtido e areia na proporção de 3:1:1 em volume, adicionando-se superfosfato simples (5 $\left.\mathrm{kg} / \mathrm{m}^{3}\right)$, cloreto de potássio $\left(3 \mathrm{~kg} / \mathrm{m}^{3}\right)$ e calcário $\left(2 \mathrm{~kg} / \mathrm{m}^{3}\right)$; composto I com a seguinte composição: esterco curtido de boi e palha de café na proporção de 1:1 em volume; composto II constituído de grama seca, palha de feijão, palha de soja, cama de carneiro e terra na proporção de 
1:1:1:1:4 em volume; vermiculita pura granulação fina; húmus (vermicomposto). Aos substratos foram adicionadas três doses do produto corretivo à base de Lithothamnium $0 \%, 5 \%$ e $10 \%$ volume por volume (v/v) de acordo com os tratamentos. . A análise dos substratos está representada no Quadro 1.

A semeadura foi feita em tubetes cônicos de 3,00 $\mathrm{cm}$ de diâmetro na parte superior, $15 \mathrm{~cm}$ de altura e $1 \mathrm{~cm}$ na parte inferior, com capacidade para $75 \mathrm{~mL}$ de substrato. Foram colocadas 2 sementes por tubete a $1,5 \mathrm{~cm}$ da borda e cobertos com a mistura relativa ao tratamento.

Foi utilizado o delineamento em blocos ao acaso com esquema fatorial $6 \times 3$ [seis substratos e três doses do corretivo à base de Lithothamnium $(0 \% \mathrm{v} / \mathrm{v}),(5 \% \mathrm{v} / \mathrm{v})$ e $(10 \% \mathrm{v} / \mathrm{v})]$, constituindo 18 tratamentos, 4 repetições e 22 plantas por parcela, perfazendo um total de 1.584 plantas a serem avaliadas.

Aos cem dias após a semeadura fez-se avaliação destrutiva das mudas que foram lavadas, fotografadas e em seguida medidas do coleto até a inserção da última folha (parte aérea) e medidas, do coleto até a extremidade da raiz. Depois de lavado em água destilada, o material foi acondicionado em sacos de papel e seco em estufa com circulação de ar forçada e temperatura de $75^{\circ} \mathrm{C}$ por $72 \mathrm{~h}$, período após o qual atingiu o peso seco constante, determinando-se então a biomassa seca da raiz e da parte aérea em balança eletrônica.

Foram efetuadas análises de crescimento, compreedendo análise de variância para comprimento de raiz em $\mathrm{cm}$, comprimento da parte aérea em $\mathrm{cm}$, número de plantas que emergiram em percentual, peso da biomassa seca da raiz em g, peso da biomassa seca da parte aérea em $\mathrm{g}$ e peso da biomassa seca total em $\mathrm{g}$.

No teste de médias foi utilizado o de probabilidade, proposto por Scoot \& Knott (1974).

\section{RESULTADOS E DISCUSSÃO}

Os resultados da interação entre diferentes substratos e doses do corretivo à base de Lithothamnium, para o comprimento da parte aérea e da raiz de mudas de citrumeleiro 'Swingle'aos 100 dias após a semeadura, bem como as porcentagens de germinação, se encontram na Tabela 1.

O composto I se destacou em todas as características avaliadas apresentando o melhor desempenho para a germinação e o crescimento das mudas. Com relação ao comprimento da parte aérea, considerando que o ponto de repicagem é $10 \mathrm{~cm}$, conforme Grassi Filho et al. (2001), pode-se observar que os substratos húmus e composto I, foram os que apresentaram melhores resultados. Carvalho (1994) cita um período entre 90 e 120 dias após a semeadura para obtenção de plantas aptas à repicagem. Serrano (2003), trabalhando com limoeiro "Cravo" em diferentes sistemas, obteve em média 73 dias para alcançar a altura de repicagem. Jabur (2001) experimentou diferentes misturas de húmus e vermiculita para limoeiro 'Cravo' e tangerineira 'Cleópatra' e obteve em média 111 dias para a repicagem. Com relação ao uso do corretivo à base Lithothamnium, apesar do pequeno incremento em alguns substratos, não houve diferença estatística com a sua utilização, exceto para o incremento negativo na dose de $10 \%$ para o substrato húmus.

O comprimento médio das raízes não apresentou diferença entre os tratamentos, salvo no substrato vermiculita sem adição do corretivo à base de Lithothamnium mostrando sua influência num substrato considerado inerte. Esta uniformidade pode ser explicada pelo recipiente utilizado (tubete) que naturalmente delimita o crescimento da raiz, concordando com resultados obtidos por Lira (1990).

No que diz respeito à germinação observa-se que apenas o composto II e o húmus com adição do corretivo à base de Lithothamnium foram influenciados negativamente na germinação das sementes. Para os demais tratamentos ainda que não tenha havido diferença estatística, o uso do corretivo à base de Lithothamnium promoveu incremento na taxa germinativa.

Houve diferença entre a biomassa seca da raiz, da parte aérea e total das plântulas em função do substrato e das doses do corretivo à base de Lithothamnium, conforme Tabelas 2 e 3 .

Observa-se novamente que os substratos, composto I e húmus se destacaram em relação aos demais. Com relação ao uso do corretivo à base de Lithothamnium é importante salientar sua influência sobre os tratamentos em questão; sua adição no tratamento húmus resultou num decréscimo na biomassa seca da raiz, da parte aérea e conseqüentemente na biomassa seca total. Em contrapartida, a utilização do corretivo à base de Lithothamnium com o composto I promoveu incremento nas características avaliadas.

O substrato vermiculita apresentou o mesmo comportamento das características anteriores, resultando em menor biomassa seca sempre quando não se utilizou o corretivo à base de Lithothamnium.

Os resultados obtidos demonstram a possibilidade de se produzir mudas cítricas a partir de substratos orgânicos, haja vista a grande demanda por estes produtos no contexto atual. $\mathrm{O}$ corretivo à base de Lithothamnium apresenta-se como mais uma alternativa de incremento nutricional para a produção de mudas cítricas. 


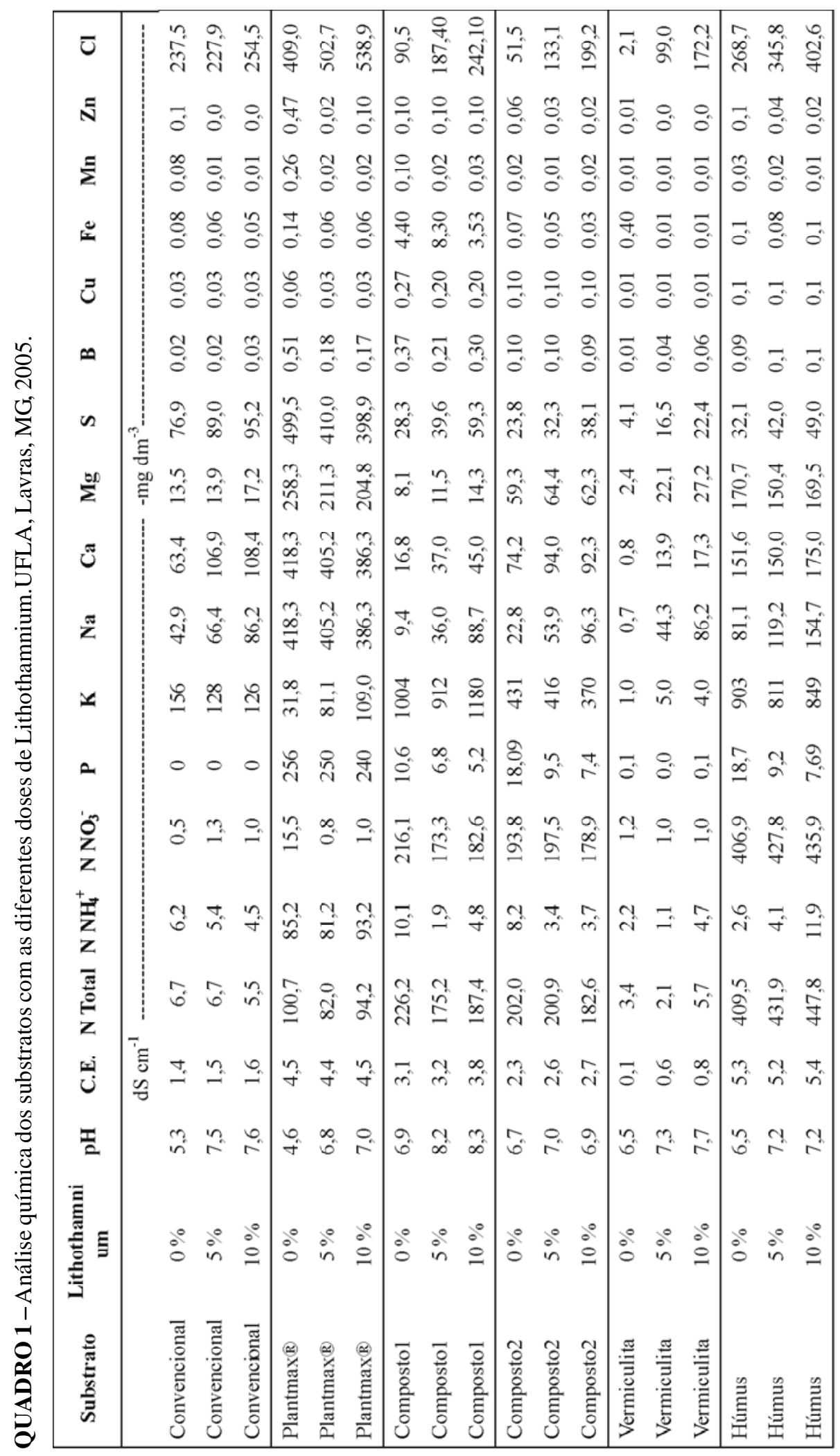

Ciênc. agrotec., Lavras, v. 31, n. 4, p. 982-988, jul./ago., 2007 
TABELA 1 - Comprimento da parte aérea e da raiz e emergência de plântulas de citrumeleiro ‘Swingle’ após cem dias da semeadura,em médias de 4 repetições. UFLA, Lavras, MG, 2005.

\section{Parte aérea (cm)}

Raiz (cm)
Emergência (\%)

\begin{tabular}{|c|c|c|c|c|c|c|c|c|c|}
\hline$\underbrace{\begin{array}{c}\text { Doses de } \\
\text { Lithothamnium }\end{array}}_{\text {Substrato }}$ & $\mathbf{0}$ & $5 \%$ & $10 \%$ & $\mathbf{0}$ & $5 \%$ & $10 \%$ & $\mathbf{0}$ & $5 \%$ & $10 \%$ \\
\hline Vermiculita & $5,60 \mathrm{c} \mathrm{A}$ & $6,18 \mathrm{c} \mathrm{A}$ & $6,55 \mathrm{c} \mathrm{A}$ & 4,20 b B & 10,04 a A & 9,94 a A & 86 a $A$ & 95 a $\mathrm{A}$ & 95 a A \\
\hline Convencional & $6,28 \mathrm{c} \mathrm{A}$ & $6,32 \mathrm{c} \mathrm{A}$ & $6,78 \mathrm{c} \mathrm{A}$ & 10,60 a $\mathrm{A}$ & 10,36 a A & 10,15 a $\mathrm{A}$ & 86 a A & 91 a $\mathrm{A}$ & 91 a A \\
\hline Composto II & $7,15 \mathrm{~b} \mathrm{~A}$ & $7,10 \mathrm{~b} \mathrm{~A}$ & $6,91 \mathrm{c} \mathrm{A}$ & 10,26 a A & 10,20 a A & 9,58 a B & $68 \mathrm{~b} \mathrm{~A}$ & $73 \mathrm{~b} \mathrm{~A}$ & $68 \mathrm{~b} \mathrm{~A}$ \\
\hline Plantmax & $7,35 \mathrm{~b} \mathrm{~A}$ & $7,38 \mathrm{~b} \mathrm{~A}$ & 7,78 b A & 10,27 a $A$ & 10,26 a $\mathrm{A}$ & 10,42 a $\mathrm{A}$ & 86 a A & 91 a A & 95 a $\mathrm{A}$ \\
\hline Húmus & 9,69 a A & 9,10 a $\mathrm{A}$ & 7,98 b B & 10,18 a $\mathrm{A}$ & 10,10 a $\mathrm{A}$ & 10,11 a $\mathrm{A}$ & 86 a A & $82 \mathrm{~b} \mathrm{~A}$ & $77 \mathrm{~b} \mathrm{~A}$ \\
\hline Composto I & 8,88 a A & 9,56 a $\mathrm{A}$ & 8,97 a A & 9,98 a B & 10,50 a A & 10,53 a $\mathrm{A}$ & 86 a A & 95 a A & 95 a A \\
\hline
\end{tabular}

* Médias seguidas pela mesma letra minúscula na vertical e maiúscula na horizontal não diferem significativamente ao nível de $5 \%$ de probabilidade pelo teste de Scoot \& Knott (1974).

TABELA 2 - Biomassa seca da raiz e da parte aérea de plântulas de citrumeleiro 'Swingle' após cem dias da semeadura, em função dos substratos e das doses do corretivo à base de Lithothamnium.UFLA, Lavras, MG, 2005.

\begin{tabular}{|c|c|c|c|c|c|c|}
\hline & \multicolumn{3}{|c|}{ Biomassa seca da raiz (g) } & \multicolumn{3}{|c|}{ Biomassa seca da parte aérea (g) } \\
\hline & $\mathbf{0}$ & $5 \%$ & $10 \%$ & $\mathbf{0}$ & $5 \%$ & $10 \%$ \\
\hline Vermiculita & $1,31 \mathrm{~b} \mathrm{~B}$ & $2,17 \mathrm{c} \mathrm{A}$ & $2,20 \mathrm{c} \mathrm{A}$ & 1,94 c B & $2,91 \mathrm{c} \mathrm{A}$ & $3,36 \mathrm{c} \mathrm{A}$ \\
\hline Convencional & $1,87 \mathrm{~b} \mathrm{~A}$ & $1,90 \mathrm{c} \mathrm{A}$ & $1,86 \mathrm{c} \mathrm{A}$ & $3,11 \mathrm{~b} \mathrm{~A}$ & $2,98 \mathrm{c} \mathrm{A}$ & $3,18 \mathrm{c} \mathrm{A}$ \\
\hline Composto II & $2,07 \mathrm{~b} \mathrm{~A}$ & $2,11 \mathrm{c} \mathrm{A}$ & $1,70 \mathrm{c} \mathrm{A}$ & $3,04 \mathrm{~b} \mathrm{~A}$ & $3,10 \mathrm{c} \mathrm{A}$ & $2,61 \mathrm{c} \mathrm{A}$ \\
\hline Plantmax & $2,29 \mathrm{~b} \mathrm{~A}$ & $2,30 \mathrm{c} \mathrm{A}$ & $2,75 \mathrm{~b} \mathrm{~A}$ & $3,61 \mathrm{~b} \mathrm{~A}$ & $3,84 \mathrm{c} \mathrm{A}$ & $4,50 \mathrm{~b} \mathrm{~A}$ \\
\hline Húmus & 4,13 a $\mathrm{A}$ & $3,23 \mathrm{~b} \mathrm{~B}$ & $2,74 \mathrm{~b} \mathrm{~B}$ & 6,70 a $A$ & $5,26 \mathrm{~b} \mathrm{~B}$ & 4,43 b B \\
\hline Composto I & 3,79 a A & 4,62 a A & 4,00 a $\mathrm{A}$ & 5,78 a B & 7,09 a A & 5,99 a B \\
\hline
\end{tabular}

* Médias seguidas pela mesma letra minúscula na vertical e maiúscula na horizontal não diferem significativamente ao nível de $5 \%$ de probabilidade pelo teste de Scoot \& Knott (1974). 
TABELA 3 - Biomassa seca total de plântulas de citrumeleiro após cem dias da semeadura em função dos substratos e das doses do corretivo à base de Lithothamnium. UFLA, Lavras, MG, 2005.

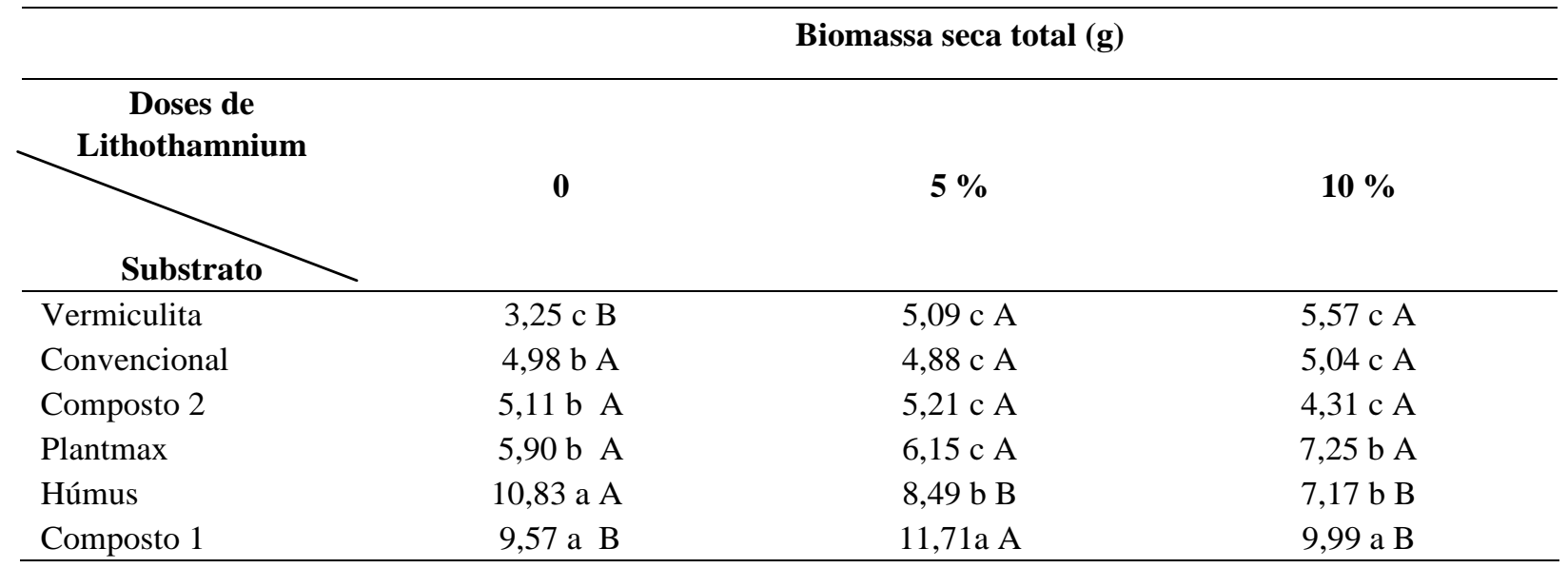

* Médias seguidas pela mesma letra minúscula na vertical e maiúscula na horizontal não diferem significativamente ao nível de $5 \%$ de probabilidade pelo teste de Scoot \& Knott (1974).

\section{CONCLUSÕES}

Húmus e composto I foram os substratos que mais se destacaram para a produção de mudas de citrumeleiro 'Swingle' até a repicagem.

O corretivo à base de Lithothamnium tem efeito no crescimento inicial de mudas de citrumeleiro 'Swingle'.

As mudas no substrato húmus (vermicomposto) apresentaram decréscimo na biomassa com o uso do corretivo à base de Lithothamnium

$\mathrm{O}$ corretivo à base de Lithothamnium propiciou melhor crescimento das mudas, quando adicionado ao composto I.

\section{REFERÊNCIAS BIBLIOGRÁFICAS}

AGROCITROS MUDAS E PRODUTOS AGRÍCOLAS LTDA. Porta-enxertos: citrumelo Swingle. Casa Branca, 2002. Disponível em: 〈http://www.citrolima.com.br〉. Acesso em: 10 out. 2004.

CARVAlHO, S. A. Propagação dos citros. Informe Agropecuário, Belo Horizonte, v. 22, n. 209, p. 21-25, 2001.

CARVALHO, S. A. Manejo da adubação nitrogenada na produção de porta-enxertos cítricos em bandejas. 1994. 74 f Tese (Doutorado em Agronomia) - Escola Superior de Agricultura de Lavras, Lavras, 1994.
GRASSI FILHO, H.; PEREIRA, M. A. A. M.; SAVINO, A. A.; RODRIGUES, V. T. Efeito de diferentes substratos no crescimento de mudas de limoeiro 'Cravo' até o ponto de enxertia. Revista Laranja, Cordeirópolis, v. 22, n. 1, p. 157$166,2001$.

JABUR, M. A. Influência de substratos na formação dos porta-enxertos: limoeiro Cravo (Citrus limonia Osbeck) e Tangerineira Cleópatra (Citrus reshni Hort. Ex Tanaka) em ambientes protegidos. 2001. 54 f. Tese (Doutorado em Agronomia) - Faculdade de Ciências Agrárias e Veterinárias, Universidade Estadual Paulista, Jaboticabal, 2001.

LE BLEU, P. Contribuitiom à l'étude des algues marines em Bretagne: bilan des leur utilizacion em milieu agricole. France: Tours, 1983. 103 p.

LIRA, L. M. Efeito de substratos e do superfosfato simples no limoeiro "cravo" (Citrus limonia cv. Cravo) até a repicagem. 1990. 85 f. Dissertação (Mestrado em Agronomia) - Escola Superior de Agricultura de Lavras, Lavras, 1990.

MATIELLO, J. B.; BARROS, C. M.; PINTO, J. F. Adubação NPK de recuperação de mudas de café formadas em tubetes. In: CONGRESSO BRASILEIRO DE PESQUISAS CAFEEIRAS, 26., 2000, Marília. Anais... Marília: [s.n.], 2000. 
POMPEU JÚNIOR, J. Porta-enxertos. In: RODRIGUEZ, O.; VIÈGAS, F.; POMPEU JÚNIOR, J.; AMARO, A. A. Citricultura brasileira. 2. ed. Campinas: Fundação Cargill, 1991. v. 1, p. 265-280.

POMPEU JÚNIOR, J. Rootstocsks and scions in citriculture of the São Paulo state. In: INTERNATIONAL CONGRESS OF CITRUS NURSERYMEN, 6., 2001, Ribeirão Preto. Anais... Ribeirão Preto: [s.n.], 2001. p. 75-82.
SCOOT, A. J.; KNOTT, M. A. A cluster analysis method for grouping means in the analysis of variance. Biometrics, Washington, v. 30, n. 3, p. 507-512, Sept. 1974.

SERRANO, L. A. L. Sistemas de produção e doses de adubo de liberação lenta na formação de porta-enxerto cítrico (Citrus limonia Osbeck cv. Cravo). 2003. 97 f. Dissertação (Mestrado em Produção Vegetal) - Universidade Estadual Norte Fluminense, Campos dos Goitacazes, 2003. 